\title{
Arquivos Afro-diaspóricos: a voz do enigma na literatura negra-feminina brasileira
}

Resumo: Partindo da reflexão de Alice Walker, a respeito da necessidade de a pessoa negra intelectual estar duplamente preparada, pois "não há apenas um mundo novo a ser conquistado, há um mundo antigo a ser reivindicado", penso a respeito da construção de arquivos afro-diaspóricos na literatura negra-brasileira, especialmente a produzida por autoras. Escolho duas obras que dão uma imagem desses arquivos: o conto "Exu e a lagartixa”, de Mãe Beata de Yemojá, do livro Caroço de Dendê (1997) e o poema "Vozes-mulheres", de Conceição Evaristo, do livro Poemas da recordação e outros movimentos (2008). Em diálogo com o pensamento de Sueli Carneiro, Lélia Gonzales, Luis Rufino e Achille Mbembe, trato das características e modos de construção destes arquivos antirrascistas, que se guiam por epistemes não brancas e não eurocentradas, e em como a literatura negra-feminina brasileira têm contribuído para a restituição de presenças, vibrações e vestígios. Neste sentido, a voz traduzida na escrita se revela fundadora.

Palavras-chave: arquivos afro-diaspóricos, literatura negra-feminina, arquivos antirrascistas, oralitura, memória

Abstract: Based on Alice Walker's reflection, about the need for the intellectual black person to be doubly prepared, as "there is not only a new world to be conquered, there is an old world to be claimed", I think about the construction of the Afro-Diasporic archives in the Black Brazilian Literature, especially that produced by female authors. I choose two works that give an image of these archives: the short story "Exu e a lagartixa", by Mãe Beata de Yemojá, from the book Caroço de Dendê (1997) and the poem "Vozes-mulheres", by Conceição Evaristo, from the book Poemas da recordação e outros movimentos (2008). In dialogue with the thought of Sueli Carneiro, Lélia Gonzales, Luis Rufino and Achille Mbembe, I deal with the characteristics and modes of construction of these anti-racist archives, which are guided by non-white and non-Eurocentered epistemes, and how Black Female Brazilian Literature has contributed to the restitution of presences, vibrations and traces. In this sense, the voice translated into writing is found to be the founder.

Keywords: Afro-Diasporic archives, black female literature, anti-racist files, oral reading, memory 


\section{Arquivo como enigma paradoxal}

Recentemente, foram publicados no Brasil os ensaios de Alice Walker. Já não era sem tempo! Como ser uma intelectual negra sem ter contato com o pensamento teórico desta autora? Estou lendo a tradução para o português de Stefanie Borges, tradutora negra e poeta que também traduziu escritos de Audre Lorde, com muito entusiasmo. Um dos textos é um discurso que Alice Walker preparou para a formatura da Faculdade de Artes Sarah Lawrence College, em 1972. Ela o intitulou "Como falar sobre quase tudo de modo breve com o coração". Só o título já é uma lição de estilo e a marcação de um lugar epistêmico. Apesar de ter conhecido o discurso por escrito, pude sentir o calor da voz de Alice, suas modulações e tonalidade, as expressões e gestos do corpo da escritora negra que admiro tanto e que realiza na temporalidade em que a leitura se faz a transmissão de uma sabedoria adquirida ao longo de anos. Me senti uma formanda emocionada diante da fala afetuosa daquela mais velha. Escolhi uma passagem desta fala para refletir sobre os arquivos afro-diaspóricos. Nela, Alice Walker alerta para a dupla tarefa de uma pessoa negra intelectual:

Se a pessoa for negra e estiver caindo no mundo, deve estar armada em dobro, preparada em dobro. Por que, para ela, não há apenas um mundo novo a ser conquistado, há um mundo antigo a ser reivindicado. (Walker 2021: 39)

Ela trata das inúmeras/os intelectuais e artistas negras/os, em especial mulheres, silenciadas/os em vida e posteriormente esquecidas/os, levadas/os a uma condição ilusória de inexistência própria do epistemicídio (termo cunhado por Boaventura dos Santos) que, através de vários mecanismos, inferioriza e apaga saberes e autorias não brancas, não eurocentradas. Em par com o homicídio, que promove a morte física, o epistemicídio promove a morte intelectual, cognitiva e espiritual dos povos colonizados, produzindo indigência cultural, como aponta Sueli Carneiro (2005: 97). Em uma palavra, o epistemicídio promove descerebração, como coloca Achille Mbembe (2018: 285). Assim, reivindicar o mundo antigo é condição de existência para as/os intelectuais negras/os do presente, que precisam construir e reparar um arquivo indispensável do passado.

O que Alice Walker ensina aos formandos do Sarah Lawrence College (e a nós, que lemos o registro escrito de sua fala) é que o investimento no "mundo antigo" é uma pré-condição para que, no presente, seja possível dizer eu e assumir a autoria da própria história de vida, que é também parte de uma trajetória coletiva. Para que pessoas negras possam caminhar com dignidade pelas estradas do novo mundo e escrever novas histórias de vida, é necessário fazer justiça a um mundo antigo esquecido, inscrever e dar existência às histórias das/os ancestrais negras/os desaparecidas/os.

Neste sentido, a tradição yorùbá tem muito a nos ensinar. Nela, a relação entre presente, passado e futuro é fluida, dinâmica e não-linear, sendo fundamental para a vida dos sujeitos guiados por esta filosofia o culto aos ancestrais e aos saberes por eles 
deixados. Muitos deuses desta tradição são, na verdade, ancestrais dos seres humanos que foram, posteriormente, divinizados. Na mitologia deste povo, transmitida oralmente através de várias fórmulas mnemônicas, há um verso para falar da complexidade de Èșù (em português, Exu ou Exú), orixá da palavra, da comunicação, dos caminhos e das possibilidades. "Èșù matou um pássaro ontem com a pedra que só atirou hoje". Nas encruzilhadas paradoxais do tempo, em que Èșù faz os erros virarem acertos, o passado não é algo estático, morto; é sim uma presença viva que interage com as atividades do presente - que alimenta o presente e é por ele alimentado -, sendo recriado a cada movimento. Este enigma paradoxal instaura a possibilidade de reinvenção do presente, do passado e do futuro. Segundo Juana Elbein dos Santos:

Èșù se identifica completamente com seu papel de filho. Como tal representa o passado, o presente e o futuro sem nenhuma contradição. Ele é o processo da vida de cada ser. É o Ancião, o Adulto, o Adolescente e a Criança. É o primeiro nascido e o último a nascer. Representando o crescimento, simboliza também a mudança. (Santos 2012: 185-186)

Acho estratégico guiar nossas práticas de arquivamento pelo princípio dinâmico de Èșù, que propicia a mudança tramada pelos filhos, intelectuais e artistas negras/os do presente, que precisam criar e dar vida ao arquivo do mundo antigo.

Luiz Rufino, na Pedagogia das encruzilhadas, nos lembra que "é na linguagem que opera parte das violências cometidas às populações negro-africanas transladadas para as Américas, como também é na linguagem que se praticam as táticas" (2019: 119). Nas encruzilhadas da linguagem, é possível fazer o erro virar acerto, a regra virar exceção e a palavra de morte virar fonte de manutenção da vida e da memória dos povos subjugados. Na literatura negra-brasileira, especialmente a produzida por mulheres, encontramos muito dessa prática das táticas de transgressão do genocídio colonial. Rufino nomeia este procedimento de "dobra na linguagem":

Dobrar a linguagem é a capacidade de, em meio aos regimes monológicos/monorracionalistas, explorar as possibilidades de se inventar polilinguista/polirracionalmente. A dobra é a astúcia daquele que enuncia para não ser totalmente compreendido, não pela falta de sentido, mas pela capacidade de produzir outros que transgridam as regras de um modo normativo. (Rufino 2019: 117)

A dobra na linguagem é como a dobra do tambor, ambos falam desde um lugar de saber não monológico, sincopado, guiado por uma lógica "alteritária”, conforme neologismo gingado do autor. Rufino reconhece no tambor um arquivo (2019: 156) de vivências e saberes ancestrais que são convocados pelo toque (pelo contato do corpo daquele que toca com o corpo sacralizado do tambor), vivências ancestres trazidas para o presente para serem experienciadas mais uma vez. Assim também é, muitas vezes, utilizada a 
linguagem pelas/os sujeitas/os afro-diaspóricas/os, que dinamizam uma língua dobrada, alimentada por línguas e saberes africanos e de povos originários das Américas. É o Pretuguês, que Lélia Gonzales tanto defendeu em sua trajetória intelectual, constituído pela contribuição das línguas banto, do yorùbá e das centenas de línguas dos povos originários do Brasil. Para construir e reparar o arquivo afro-diaspórico, a/o intelectual negra/o precisa estar atenta/o à linguagem, justo porque é através dela que o epistemicídio é operado e reproduzido. Me parece que para driblar a lógica colonial plasmada na língua do colonizador, para dobrar a linguagem e validar o pretuguês, é preciso ouvir. Ter os ouvidos abertos para aprender com a tradição oral, com suas mestras e mestres, que estabelecem outros parâmetros para a escrita do arquivo afro-diaspórico.

Seguindo esta trilha, acho importante reconhecer as contribuições literárias de Beatriz Moreira Costa, Mãe Beata de Yemonjá. Nascida em Salvador, na Bahia, em 1931, cresceu na cidade de Cachoeira do Paraguassu, migrando posteriormente para o Rio de Janeiro. Yalorixá do Ilé Omi Ojú Àró (Casa das águas dos olhos de Oxóssi), em Nova Iguaçu, no Rio de Janeiro, foi ativista do movimento negro, figura pública importante, dedicou-se, entre suas muitas atividades, ao exercício literário. Tem publicados dois livros de literatura, Caroço de dendê (Pallas, 1997) e Histórias que minha avó contava (Terceira margem, 2004), além de pequenos textos publicados em coletâneas como Guerreiras da natureza: mulher negra, religiosidade e ambiente (Selo Negro, 2008) e O livro da saúde das mulheres negras: nossos passos vêm de longe (Pallas/ Criola, 2006). Seus dois livros de literatura são, hoje, verdadeiras relíquias, o que não acho nada positivo; a dificuldade de acesso a estas obras é sinal de que precisam ser reeditadas. Na introdução ao Caroço de dendê, a pesquisadora Vânia Cardoso diagnostica algo importante:

O livro de Mãe Beata significa uma abertura do pequeno espaço na literatura brasileira para a mulher negra enquanto autora, enquanto voz criativa na arte de contar histórias. [...] Apesar da manutenção desta tradição oral de se contar mitos e histórias sagradas ser frequentemente atribuída, tanto por pesquisadores como pelo próprio 'povo de santo', às mulheres mais velhas dessas comunidades, a quase inexistência de textos publicados por essas mulheres é marcante. (Beata de Yemonjá 2002: 15)

A quase inexistência de textos publicados por mestras da literatura oral e o pouco reconhecimento do valor das obras escritas e publicadas (apesar dos entraves) por elas revela o epistemicídio operando dentro do sistema literário. Muitas vezes estes textos são reconhecidos por seu valor antropológico, mas não chegam a ser analisados em seus aspectos propriamente literários.

As obras de Mãe Beata são fundamentais para a construção de um arquivo afro-diaspórico brasileiro baseado na voz. Na biografia desta escritora, disponível no portal Literafro, sua importância neste sentido é apontada: 
Hábil contadora de histórias, buscou sempre resguardar em seus relatos as tradições e heranças da cultura africana, que passou a conhecer desde a infância cercada por descendentes de ex-escravos. Jovem ainda, já arquivava e difundia essa memória coletiva, com histórias e mitos que permeiam a formação da cultura afro-brasileira.

Sem menosprezar as qualidades literárias do texto, que também guardam a memória de uma episteme afro-diaspórica, proponho a leitura de um dos contos de Mãe Beata, publicado em Caroço de dendê:

\section{Exu e a lagartixa}

Exu sempre teve muitos problemas com Oxalá, pois ele não queria receber as suas ordens. Um dia, Oxalá pediu a Exu que fosse procurar um camaleão, pois ele tinha que ter um em sua casa, pois o mesmo faz parte da sua vida. O que fez Exu? Ficou matutando e disse com seus botões:

- Agora, veja! Este velho querendo me fazer de empregado dele. Como é que pode?! Eu que tenho tanto poder! Poder de plantar uma semente hoje e a mesma germinar, crescer e dar frutas deliciosas o mesmo dia, de fazer chover e fazer sol na mesma hora, de dividir um ser humano em dois, de um lado ser um homem e do outro ser mulher, de matar um pássaro hoje com uma pedra que joguei ontem. Vou mostrar a ele quem sou eu!

E saiu. No caminho encontrou uma lagartixa, passou a mão e a transformou em camaleão. Ele a levou para Oxalá, pensando que o estava enganando. Chegou fingindo que estava feliz porque estava fazendo um favor para Oxalá, que lhe disse:

- Modupé! Obrigado meu amigo. Agora eu vi que você gosta mesmo de mim, e é de minha inteira confiança. Ponha o camaleão aqui perto de mim.

Exu, pensando que enganava Oxalá, perguntou:

- Está satisfeito, Babá?

- Como não havia de estar? Eu vou pôr o nome dele, Omonilê - respondeu Oxalá.

Oxalá soprou para a lagartixa, que mudou de cor, ficou cinza e começou a subir pelas paredes. Exu saiu correndo, envergonhado. Logo, você veja, não se deve menosprezar os mais velhos. É por isso que a lagartixa também é filha de Oxalá, e não se deve matar quem é filho de Oxalá.

(Beata de Yemonjá 2002: 95)

Neste conto, vemos o caráter híbrido do pretuguês, em que palavras do yorubá, ("Exu”, "Oxalá”, "Modupé", "Omonilê") e de línguas banto (como "matutando"), com as grafias adaptadas, estão incorporadas a português brasileiro. Também é interessante perceber o deslizamento entre os registros - ora mais formal, ora mais coloquial -, acompanhado pelo tom de conversa com quem ouve-lê. $\mathrm{O}$ apelo àquele que participa do texto ouvindo-lendo, marca da literatura oral, está presente em expressões como "Agora, veja!", "Você veja" e "O que fez Exu?". O dinamismo da oralidade se manifesta mais uma 
vez na variação do verso definidor de Ėșù, que Mãe Beata apresenta em uma nova versão que não exclui a outra mencionada por mim antes. A variação também marca a presença de um tempo não-ocidental, herança dos povos do continente africano. Amadou Hampâté Bâ, griot da região do atual Mali, em Amkoullel, o menino fula, trata do caráter atemporal das narrativas, que observo também no conto de Mãe Beata:

Como a cronologia não é uma grande preocupação dos narradores africanos, quer tratem de temas tradicionais ou familiares, nem sempre pude fornecer datas precisas. [...] Nas narrativas africanas, em que o passado é revivido como uma experiência atual de forma quase intemporal, às vezes surge certo caos que incomoda os espíritos ocidentais. Mas nós nos encaixamos perfeitamente nele. Sentimo-nos à vontade como peixes num mar onde as moléculas de água se misturam para formar um todo vivo. (Bâ 2013: 11-12)

Os griots africanos são verdadeiras bibliotecas vivas e Mãe Beata continua esta tradição, tendo também exercido este papel de biblioteca viva. Ela faleceu em 2017, daí a importância de ter deixado livros em que ela mesma fez a tradução do registro oral para o escrito. É claro que sua transmissão oral continua a produzir efeitos na memória coletiva dos seus filhos de santo e povos de terreiro, porém, em uma sociedade grafocêntrica e monorracional, o registro escrito é uma arma de disputa do saber e da memória importante para construção do arquivo afro-diaspórico. Segundo Vânia Cadoso,

a publicação dos contos de Mãe Beata significa a remoção dessas histórias do limite dos terreiros e sua inserção num contexto ainda mais amplo da cultura brasileira. Esse processo implica uma 'tradução' dos contos de uma linguagem falada para uma narrativa escrita, uma modificação do próprio 'ato de contar'. (Beata de Yemojá 2002: 14)

A narrativa "Exu e a lagartixa" flagra um dos episódios da relação entre Òrìșàlá (em português, Oxalá) e Ėșù, deuses que viveram juntos durante 16 anos. Òrișàlá é o orixá mais velho de todo o panteão yorùbá, ele participa da criação do mundo junto a Olódùmarè, o grande criador, e é responsável pela criação e modelagem dos seres humanos. Apesar de Ėșù também ser importante na criação do mundo e ser o orixá que come primeiro nos rituais, neste conto ele precisa aprender a respeitar o orixá mais velho. Èșù, pretensiosamente, quer mostrar o seu poder à Òrișàlá, mas, ao final da narrativa, é Òrișàlá quem lhe revela a sua real dimensão.

É interessante que a história tem como mote a ordem de Òrișàlá para que Èșù lhe trouxesse um camaleão, animal altamente simbólico dentro do complexo mítico-filosófico yorùbá. O camaleão é um dos primeiros seres a povoar a Terra e ele representa o olhar plural, que consegue perceber diferentes perspectivas, além de ser dotado da capacidade de se transmutar e se adaptar aos ambientes. 
O conto transmite o saber através da lógica da dobra e do enigma. Ao final, o ensinamento ancestral é sintetizado pela narradora: a importância de se respeitar os mais velhos, de não subestimar o saber daqueles que vieram antes. Apesar de Ėșù ter poderes extraordinários, ele não é capaz de enganar Òrị̀àlá, o ancião, orixá fun fun associado ao ar que penetra e anima todos os corpos, à pureza do pano branco e à disciplina. 0 dinamismo de Ėșù deve servir ao mais velho, reconhecendo sua sabedoria, aprendendo e guiando-se por ela. É essa uma imagem para o arquivo afro-diaspórico.

\section{Arquivo como comunidade escrevivida}

Na literatura brasileira contemporânea, há um poema-monumento que torna audíveis e memoráveis as vozes de mulheres negras vitimadas pelo estado colonial, que se mantém vigente no regime democrático. Leio este poema lembrando das imagens recentes da derrubada da estátua de Borba-Gato, em São Paulo, e do incêndio no monumento intitulado Descobrimento, em que são retratados Pedro Álvares Cabral, Pero Vaz de Caminha e Frei Henrique de Coimbra, no bairro da Glória, no Rio de Janeiro. Se para tentar frear a repetição do mecanismo colonial de pilhagem, morte e destruição é indiscutivelmente importante derrubar monumentos em homenagem a bandeirantes, líderes católicos e agentes da Colônia Portuguesa, precisamos também erguer novos monumentos que coloquem em disputa o poder de enunciar o presente, o passado e o futuro.

Falo de "Vozes-mulheres", de Conceição Evaristo, publicado nos anos 90 nos Cadernos Negros, um marco da poesia brasileira contemporânea ainda não suficientemente reconhecido:

\section{Vozes-mulheres}

A voz de minha bisavó
ecoou criança
nos porões do navio.
Ecoou lamentos
De uma infância perdida.

A voz de minha avó

ecoou obediência

aos brancos-donos de tudo.

A voz de minha mãe

ecoou baixinho revolta

no fundo das cozinhas alheias

debaixo das trouxas

roupagens sujas dos brancos 

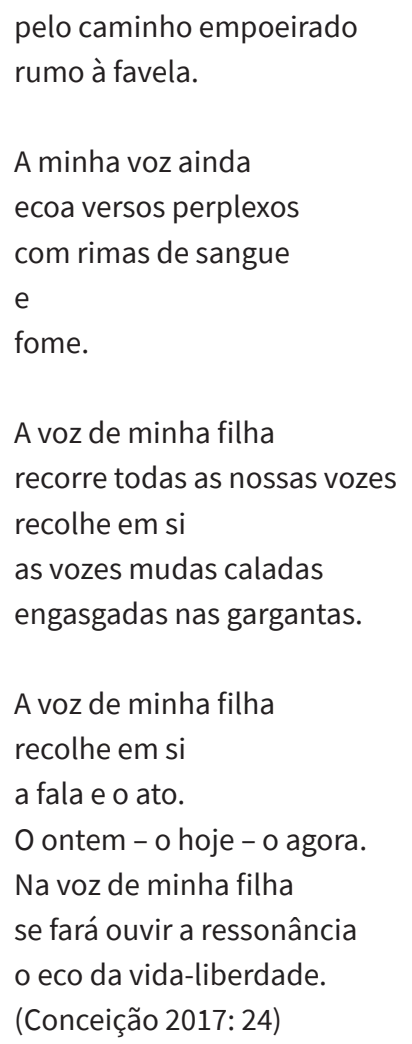

O poema atravessa séculos da História do Brasil, assumindo uma dimensão épica apesar da concisão de sua narrativa. As estrofes nos propõem um exercício de escuta dos lamentos, sussurros, revoltas em voz baixa que ainda ecoam no presente, desde o fundo dos tumbeiros, lavouras, senzalas, cozinhas, barracos e quilombos, como vibrações fantasmáticas. Uma outra dimensão de tempo, não-linear e não-fragmentada, é instaurada para tornar essas vozes sensíveis no presente.

A história da diáspora africana é contada a partir da perspectiva de mulheres que não costumam ser lembradas, apesar de terem sido (e ainda serem) as guardiãs da memória dos saberes africanos. As mulheres negras, historicamente, desempenharam importante papel na inscrição de epistemologias afro-diaspóricas na cultura brasileira, recolhendo e alinhavando os fragmentos das culturas violentadas pelo tráfico intercontinental, sobrepondo esses retalhos de memória aos códigos da cultura do colonizador, o que permitiu que se criasse para o saber ancestral novos sentidos e possibilidades de sobrevivência. As religiões de matriz africana, lideradas por mulheres negras, têm sabidamente um papel importante nesta manutenção da memória afro-diaspórica, de transmissão oral, como bem coloca a poeta e prosadora Mel Adún: "A escolha da voz é feminina. Elas são 
contadoras de histórias, já que a religião de matriz africana no Brasil foi e é sustentada por elas. Com a presença dessas mulheres negras, contadoras de histórias oficiais ou não, a cultura africana sobreviveu no Brasil..." (apud Duke 2016: 84). Muito das filosofias de povos africanos foi preservada na diáspora na forma de versos, provérbios, cantigas e itans, narrativas sagradas, gêneros orais de transmissão.

O poema reconhece o valor das experiências transmitidas pelas vozes (ainda que emudecidas ou caladas) de mulheres negras sobreviventes ao holocausto que foi o tráfico negreiro, do qual suas/seus descendentes ainda não se recuperaram. Através da narrativa dessas vibrações atemporais, o poema reorganiza a história do país, erguendo um arquivo contra o esquecimento e contra a desumanização dos africanos e seus descendentes. A $1^{\circ}$ pessoa do poema se apresenta através da reconstrução do coral de vozes que dá materialidade à memória de uma linhagem matrilinear: a voz da bisavó criança, sequestrada em um tumbeiro; a voz da avó, escravizada na Casa-Grande; a voz da mãe, silenciada na cozinha da família burguesa, herdeira dos sinhôs e sinhás; a voz da filha, que diz eu e ergue o monumento às suas ancestrais; a voz da filha da filha, que faz ressoar todas as vozes que lhe antecederam e carrega a esperança de liberdade. Em uma gradação crescente, as vozes se somam e amplificam.

O poema vai contra a lógica da perda operada pelo regime colonial que, para desumanizar os africanos, destruiu, dentre tantas coisas, laços familiares, genealógicos e territoriais. Assim, aqueles que foram submetidos à condição de "sem parentes" são marcados pelo desejo de reconstituir uma comunidade, que possa "fazer nascer um vínculo e fazer surgir um lugar com base nos quais nos possamos manter de pé em resposta a uma longa história de sujeição e de fratura biopolítica." (Mbembe 2018: 71). Esse é um dos sentidos que o filósofo camaronês Achille Mbembe reconhece no gesto de apelar à raça, quando feito por sujeitas/os negras/os: fazer surgir uma comunidade.

Ao tratar do que ele chama de razão negra, Mbembe distingue duas escritas: uma denominada consciência ocidental do negro, fabulação que cria o negro como exterioridade inferior em relação ao branco, e que tem como resultado a produção deste último como raça superior; e outra denominada consciência negra do negro, pela qual me interesso mais neste momento:

Essa segunda escrita apresenta alguns traços distintivos, que se devem sucintamente recordar. Em primeiro lugar, ela se esforça por fundar um arquivo. Acreditamos que a instauração de um arquivo é indispensável para restituir os negros à sua história, mas é uma tarefa extraordinariamente complicada. Com efeito, nem tudo o que os negros viveram como história necessariamente deixou vestígios; e nos lugares onde foram produzidos, nem todos os vestígios foram preservados. Assim, como é que, na ausência de vestígios, de fontes dos fatos historiográficos, se escreve a História? (Mbembe 2018: 62-63) 
Como construir um arquivo do que não deixou vestígios? É a encruzilhada paradoxal em que nos lança o filósofo, que sabe das oportunidades geradas pelos enigmas. Muitas autoras e autores negras/os brasileiras/os estão produzido uma literatura que expressa esta necessidade de escrever a História sob uma ótica contra-colonial, contribuindo para a construção colaborativa de arquivos antirrascistas que se contrapõem ao arquivo da consciência ocidental do negro, criado pelos dominadores branco-europeus. No arquivo afro-diaspórico antirrascista, o velho mundo é reivindicado, conforme a lição de Alice Walker.

Através da literatura, nos tornamos mais capazes de identificar vestígios sutis pelas percepções múltiplas, não racionais, que permitem acessar tempos não cronológicos e não hegemônicos. No poema "Vozes-mulheres", as vozes são recriadas desde uma vivência íntima, ontológica e mesmo espiritual da autora, que se dobra sobre si mesma e sobre a história de suas ancestrais. Ao longo de sua obra, Conceição Evaristo elabora um conceito para nomear este movimento, que ela identifica não só em sua escrita, mas também na de outras autoras negras-brasileiras: a escrevivência. No ensaio "Gênero e etnia: uma escre(vivência) de dupla face", ao evocar o valor das obras de Geni Guimarães, Esmeralda Ribeiro, Miriam Alves, Mãe Beata de Yemonjá, Carolina Maria de Jesus, dentre outras, descreve a escrevivência:

Essas escritoras buscam na história mal-contada pelas linhas oficiais, na literatura mutiladora da cultura e dos corpos negros, assim como em outros discursos sociais, elementos para comporem as suas escritas. Debruçam-se sobre as tradições afro-brasileiras, relembram e bem relembram as histórias de dispersão que os mares contam, se postam atentas diante da miséria e da riqueza que o cotidiano oferece, assim como escrevem às suas dores e alegrias íntimas. (Evaristo 2005: 7)

Mais do que uma escrita das vivências, a escrevivência é um modo de mulheres negras assumirem o lugar da autoria, da possibilidade de dizer eu, ao reivindicarem o mundo antigo, como nos dizia Alice Walker. A escrevivência, portanto, assume um lugar ético e estético que contesta a perspectiva racista presente na História oficial e também em muitas obras que compõem o cânone literário brasileiro. É neste sentido que Conceição Evaristo fala da escrevivência como uma vingança: "Escrever pode ser uma espécie de vingança, às vezes fico pensando sobre isso. Não sei se vingança, talvez desafio, um modo de ferir o silêncio imposto, ou ainda, executar um gesto de teimosa esperança." (idem: 2). Esse gesto faz vingar o arquivo afro-diaspórico, que produz respostas ao arquivo da consciência ocidental do negro, que é branco, epistemicida e racista.

A escrevivência, realizada por escritoras negras, realiza o movimento de relembrar e de ouvir as vozes ancestrais, rompendo com as muitas camadas de silêncio imposto. Neste movimento de voltar-se para o passado, como faz a sankofa (ideograma da escrita Adinkra, do povo Akan), a autora encontra a oralidade, a comunicação que mobiliza o corpo inteiro, e que se faz presente na escrevivência de escritoras negras brasileiras. 
Do tempo/espaço aprendi desde criança a colher palavras. A nossa casa vazia de móveis, de coisas e muitas vezes de alimento e agasalhos, era habitada por palavras. Mamãe contava, minha tia contava, meu tio velhinho contava, os vizinhos amigos contavam. Eu, menina repetia, inventava. Cresci possuída pela oralidade, pela palavra. As bonecas de pano e de capim que minha mãe criava para as filhas nasciam com nome e história. Tudo era narrado, tudo era motivo de prosa-poesia. (idem: 1 )

É desta formação primeira pela literatura oral, pelo prazer de ouvir e contar histórias coletivamente, comunitariamente, que a escrevivência se desenvolve. Novamente surge a memória do Griot e de sua expertise, que foi vivida por Conceição em sua infância e que ela traduziu, quando adulta, em estilo de escrita. No prefácio ao "Becos da memória", Conceição Evaristo discorre sobre a gênese de seu romance mais importante e aborda o conceito de escrevivência:

Ali busquei escrever ficção como se estivesse escrevendo a realidade vivida, a verdade. $\mathrm{Na}$ base, no fundamento da narrativa de ‘Becos' está uma vivência, que foi minha e dos meus. Escrever 'Becos' foi perseguir uma 'escrevivência'. Por isso também busco a primeira narração, a que veio antes da escrita. Busco a voz, a fala de quem conta, para se misturar à minha. Assim nasceu a narrativa de 'Becos da memória'. Primeiro foi o verbo de minha mãe. Ela, D. Joana, me deu o mote: 'Vó Rita dormia embolada com ela'. A voz de minha mãe a me trazer lembranças de nossa vivência [...] A entonação da voz de mãe me jogou no passado, me colocando face a face com o meu eu menina. Fui então para o exercício de escrita. E como lidar com uma memória ora viva, ora esfacelada? Surgiu então o invento para cobrir os vazios de lembranças transfiguradas. Invento que atendia ao meu desejo de que as memórias aparecessem e parecessem inteiras. (idem: 11)

Uma escrita que nasce da voz, uma oralitura que é registrada e, assim, pode ser usada como uma arma contra o epistemicídio. A pergunta de Mbembe, anteriormente citada por mim, retorna aqui, mais uma vez, em forma de enigma: "E como lidar com uma memória ora viva, ora esfacelada?" A autora responde ao enigma com a escrevivência, que é uma estratégia epistêmica afrocentrada, contra-epistemicida, que alimenta o arquivo afro-diaspórico. Este arquivo não representa o passado, mas o constrói como um legado para que possamos existir no presente e para que futuras gerações de negras/os-brasileiras/os possam exercer o direito básico de dizer eu. 
* Heleine Fernandes é poeta, professora e pesquisadora de Poesia Contemporânea Negra-Brasileira no Laboratório Estudos Negros, pertencente ao Programa Avançado de Cultura Contemporânea - PACC/UFRJ. Doutora em Teoria Literária pela Universidade Federal do Rio de Janeiro. Autora do livro de crítica literária "A poesia negra-feminina de Conceição Evaristo, Lívia Natália e Tatiana Nascimento" (editora Malê, 2020) e do livro de poemas "Nascente" (editora Garupa e Ksa1, 2021). Participou das antologias Cult\#1, "Ato poético: poemas para a democracia" (editora Oficina Raquel, 2020) e "Carolinas: a nova geração de escritoras negras brasileiras" (editora Bazar do Tempo e FLUP, 2021).

\section{BIBLIOGRAFIA}

Bâ, Hampâté Bâ (2013), Amkoullel, o menino fula, São Paulo, Palas Athena, Acervo África. Beata de Yemonjá, Mãe (2002), Caroço de dendê: a sabedoria dos terreiros: como lalorixás e Babalorixás passam seus conhecimentos a seus filhos, Rio de Janeiro: Pallas. [1997] -- (2006), "Tradição e religiosidade", in Werneck, Jurema. O livro da saúde das mulheres negras: nossos passos vêm de longe, Rio de Janeiro: Pallas/ Criola.

-- (2008), “Primeiras palavras”, in Nascimento, Elisa Larkin. Guerreiras da natureza: mulher negra, religiosidade e ambiente. São Paulo, Selo Negro.

Carneiro, Aparecida Sueli (2005), A construção do outro como não-ser como fundamento do ser, Tese apresentada ao Programa de Pós-Graduação em Educação da Universidade de São Paulo. Disponível em https://docgo.net/philosophy-ofmoney. html?utm_source=epistemicidio-sueli-carneiro-pdf

Duke, Dawn (2016), A escritora afro-brasileira: ativismo e arte literária, Belo Horizonte, Nandyala.

Evaristo, Conceição (2017), Poemas da recordação e outros movimentos, Rio de Janeiro, Malê [2008].

-- (2017), Becos da memória, Rio de Janeiro, Pallas. [2006]

-- (2005), "Gênero e Etnia: uma escre(vivência) de dupla face", in Mulheres no Mundo Etnia, Marginalidade e Diáspora, org. Nadilza Martins de Barros Moreira \& Liane Schneider, João Pessoa, UFPB/ Ideia/Editora Universitária, disponível em http:// nossaescrevivencia.blogspot.com/2012/08/genero-e-etnia-uma-escrevivencia-de. html 
Gonzales, Lélia (1984), "Racismo e sexismo na cultura brasileira”, in Revista Ciências Sociais Hoje, ANPOCS, disponível em https://edisciplinas.usp.br/pluginfile.php/4584956/ mod_resource/content/1/06\%20\%20GONZALES\%2C\%20L\%C3\%A9lia\%20\%20 Racismo_e_Sexismo_na_Cultura_Brasileira\%20\%281\%29.pdf Lopes, Nei (2012), Novo dicionário banto do Brasil, Rio de Janeiro, Pallas. Mbembe, Achille (2018), Crítica da razão negra, São Paulo, n-1 edições. Napoleão, Eduardo (2011), Vocabulário Yorubá. Rio de Janeiro, Pallas.

Rufino, Luiz (2019), Pedagogia das encruzilhadas, Rio de Janeiro, Mórula Editorial.

Santos, Juana Elbein dos (2012), Os nagô e a morte: Pàde, Àsèsè e o culto Égun na Bahia, Petrópolis, Vozes.

Souza, Heleine Fernandes (2020), A poesia negra-feminina de Conceição Evaristo, Lívia Natália e Tatiana Nascimento, Rio de Janeiro, Malê.

Walker, Alice (2021), Em busca dos jardins de nossas mães: prosa mulherista, Rio de Janeiro, Bazar do tempo. 